\title{
Phytochemical Screening and Evaluation of Antimicrobial and Antioxidant Activity of Mahonia napaulensis (Jamanemandro) Bark Extract
}

\author{
Ranjan Paudel ${ }^{1,2}$, Rabi Kiran Sharma ${ }^{1}$, Shreeya Bhandari², Manan Koirala ${ }^{2}$, \\ Ganesh Bhandari', Netra Lal Bhandari ${ }^{*}$ \\ ${ }^{1}$ Department of Chemistry, Tri-Chandra Multiple Campus, Tribhuvan University, Kathmandu, Nepal \\ ${ }^{2}$ Department of Pharmacy, Karnali College of Health Science, Purbanchal University, Kathmandu, Nepal
}

\section{*CORRESPONDENCE:}

Netra Lal Bhandari

Department of Chemistry, Tri-Chandra Multiple Campus, Tribhuvan University, Kathmandu, Nepal

Email: netra.tu.edu@gmail.com

ISSN : 2382-5359(Online), 1994-1412(Print)

DOI:

https://doi.org/10.3126/njst.v20i1.39429

\section{ACCESS THE ARTICLE ONLINE}

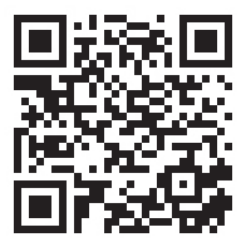

\section{CONFILICT OF INTEREST: None}

Copyright: The Author(s) 2020. This is an open access article under the $\mathrm{CC} \mathrm{BY}$ license.

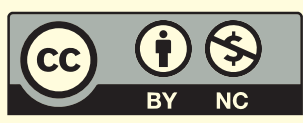

\begin{abstract}
Mahonia napaulensis also known as "Jamanemandro" in Nepali is a medium-sized stiff evergreen shrub widely distributed in South East Asia at an altitude of $1000-2000 \mathrm{~m}$, is traditionally used to treat dysentery and eye inflammation. This research focuses on screening of the phytochemicals, antimicrobial, and antioxidant properties of this plant. The methanolic extract was prepared using a Soxhlet apparatus. The antioxidant properties of extract were carried out by $50 \%$ inhibitory concentration $\left(\mathrm{IC}_{50}\right)$ values from 2-2-diphenyl-1-picrylhydrazyl (DPPH) radical scavenging. The phytochemical screening confirmed the presence of terpenoids, reducing sugars, tannins, alkaloids, glycosides including cardiac glycosides and steroids. The antimicrobial activity was studied using the disc diffusion method in five different human pathogens named Escherichia coli, Staphylococcus aureus, Pseudomonas aeruginosa, Salmonella typhi, and Shigella spps. The methanol extract was compared with standard chloramphenicol and showed that methanolic extract of is M.napaulensis exhibit maximum effect against $S$. aureus with higher growth inhibition zones (27.3 $\mathrm{mm}$ ), followed by $P$. aeruginosa, Shigella spps., $E$. coli and $S$. typhi. These antimicrobial properties showed similar effect to that of positive control, chloramphenicol. The $\mathrm{IC}_{50}$ values from $\mathrm{DPPH}$ radical scavenging were $230.89 \mu \mathrm{g} / \mathrm{mL}$ and $182.73 \mu \mathrm{g} / \mathrm{mL}$ of methanol extract and ascorbic acid, respectively. Due to this antimicrobial and antioxidant properties of $M$. napaulensis it was widely applicable in biomedical field.
\end{abstract}

Keywords: Mahonia napaulensis, screening, antioxidant, DPPH radical scavenging, $\mathrm{IC}_{50}$

\section{INTRODUCTION}

Many plants are being used as medicines conventionally from the beginning of ancient civilization to cure many healthrelated complications (Tapsell et al. 2006; Bhandari et al. 2017). Traditional medicine is used to maintain health as well as to prevent, diagnose, improve or treatment of physical and mental illness (Che et al. 2017; Silwal et al. 2020; Bhandari et al. 2020). According to the WHO's data, $80 \%$ of rural areas depend on herbal medicine as the primary health care system, and $25 \%$ of prescribed drugs are derived from plants (Basyal \& Bhandari 2019; Andreicut et al. 2018). These plants traditionally used for the treatment are investigated inadequately, or the findings have not been correlated 
with phytochemical and pharmacological properties due to potential adverse effects. These problems need to be addressed properly for the rational use of herbal medicines (Ekor 2014). The increase in multiple drug resistance in bacteria has also become a major threat to public health (Bhandari et al. 2020). The plant extracts and their effect on microorganisms have been studied worldwide that can serve as a potential source for new antimicrobial drugs (Sibanda \& Okoh 2007; Bhandari et al.2020). Nepal is in the Himalayas lap, is considered as the focal point for herbs related research. Nepal is being a habitat for more than ten thousand herbs in its alpine belt representing 6076, as flowering plants under 1534 genera and 216 families. About $5 \%$ of herbal plants are endemic to the country, while almost $30 \%$ of herbal plants are habituated in the Himalayan range (Gyawali et al. 2020). The database listing for Nepal shows 1624 species of medicinal and aromatic species (Bhattarai \& Karki 2004).

Mahonia napaulensis belongs to the family Berberidaceae and is known as "Jamanemandro" in Nepali and "Michikiswan" in Newari. It is a medium-sized fully hardy perennial evergreen shrub with yellow flowers in winter. This shrub has an ultimate height of about $6 \mathrm{~m}$ or 19.7 feet. Its origin has been said to be in Nepal. It is widely distributed in the high mountainous areas at an altitude of about 1000-2000 m in Nepal, Sikkim, Bhutan, China, Vietnam, and other countries. It is traditionally used to treat dysentery, inflammation to the eyes, antibacterial, and antioxidant properties (Manandhar 1991; Jian-Ming \& Qing 2015). The methanolic extract of $M$. napaulensis showed a broad spectrum of antimicrobial activity which might be due to the presence of alkaloids and flavonoid (Gyawali et al. 2020). Ethanolic extract of Mahonia leaves and bark are good anti inflamatory properties and antioxidant candidates (Nguyen et al. 2018). M. napaulensis has suitable antioxidant properties even on leaves of this plant (Nguyen et al. 2018). The total content of polyphenols and flavonoid in the methanol extract of the studied species positively correlated with their antioxidant properties, confirming their major role in antioxidant activity of those species (Stankovic et al. 2016). The qualitative phytochemical screening of this plant showed the chemical constituents such as alkaloids, glycosides, cardiac glycosides, carbohydrates, phenols, flavonoids, tannins, etc. (Lamichhane 2014; Riaz et al. 2015). Qualitative analysis of isoquinoline alkaloid using ethanolic extract of root of Mahonia species suggest the presence of quaternary protoberberines as prominent compound (Singh et al. 2017).

A little work has been done initially related to this plant's therapeutic properties (Gyawali et al. 2020; Thusa \& Mulmi 2017), primarily ethanolic extract using its leaves and stem. In this approach, the study was made using methanol extract of dried bark. The research is aimed to discuss the phytochemical composition, antibacterial, and antioxidant property of methanol extract from the bark of M. napaulensis. It helps to document the plant parts on a scientific basis for the traditional use of this plant as a beneficial drug. It also provides a qualitative result of this herbal medicine to meet regulatory requirements and technical support as well as a guide for the promotion, development, and regulation of herbal medicines and their undying therapeutic uses and opportunities.

\section{MATERIALS AND METHODS}

\subsection{Plant Collection, Identification and Processing}

The fresh bark of M. napaulensis was collected in March from the Pashupati areas of Kathmandu and was authenticated by National Herbarium Center Godawari, Lalitpur, Nepal. Herbarium of plant species no 54, was deposited in the Karnali College of Health Science, Gaushala, Kathmandu. The sample was dried in shaded area for a month and crushed into coarse/fine powders by using a grinder and sieved.

\subsection{Selection of Solvents and Extraction Process}

The powdered crude drug was extracted using the Soxhlet apparatus using methanol as solvent for 20 hours. The extract was made to concentrate by evaporating the solvent on a water bath and then rotary evaporator and stored in a refrigerator.

\subsection{Phytochemical Analysis}

The phytochemical examination was carried out from methanol extracts as per standard methods for the detection of alkaloids, saponins, tannins, flavonoids, terpenoids, resins, phenols, protein and amino acids, phytosterol, carbohydrate, glycosides, fixed oils, and fats (Amin et al. 2013).

\subsection{Antimicrobial Test}

The media used in this study was nutrient agar, MuellerHinton agar, and Mac-Conkey agar. Microorganisms such as S. aureus (ATCC 25923), S. typhi (clinical strain), E. coli (ATCC 25922), Shigella spps. (clinical strain), and P. aeruginosa (ATCC 27853) were obtained from National Public Health Laboratory Biosafety, Teku, Kathmandu, Nepal. The microorganisms were kept under the refrigerator $\left(4{ }^{\circ} \mathrm{C}\right)$ until use. The methanolic extract of 
various concentration was prepared for antimicrobial test, and $10 \mu \mathrm{L}, 20 \mu \mathrm{L}$ of the extract at different concentrations were loaded on sterile discs measuring $6 \mathrm{~mm}$ in diameter, so that the concentration of the extract on each disc is $10,000 \mu \mathrm{g}, 5,000 \mu \mathrm{g}, 2,500 \mu \mathrm{g}, 1,250 \mu \mathrm{g}$, and $625 \mu \mathrm{g}$, respectively. The disks were kept in aseptic condition. The disk diffusion method was used to determine the bacterial growth inhibition by methanol extract of $M$. napaulensis. The bacteria culture solution was kept in Mac-Conkey agar and nutrient agar at $37^{\circ} \mathrm{C}$. The culture solution of bacteria to be used was isolated in the respective media. Then it was transferred in nutrient broth and was left in the incubator for 2 hours. After 2 hrs nutrient broth was checked with standard Mac-farland. After analyzing Mac-farland the respective bacteria were inoculated in Mueller-Hinton Agar (MHA) using a cotton swab in a sterile condition. A disc with the extract and standard solution was placed on the medium with both negative and positive controls. The MHA plate was incubated at $37^{\circ} \mathrm{C}$ for 24 hours. After incubation, the zone of inhibition was measured with the help of scale. The antimicrobial activity of the extract was assessed by the presence or absence of a zone of inhibition (ZOI), and the diameter of the ZOI was measured (Bhandari et al. 2019). The chloramphenicol was used as a reference drug. The growth and zone of inhibition of $S$. aureus and other bacteria is presented in Fig. 1 .
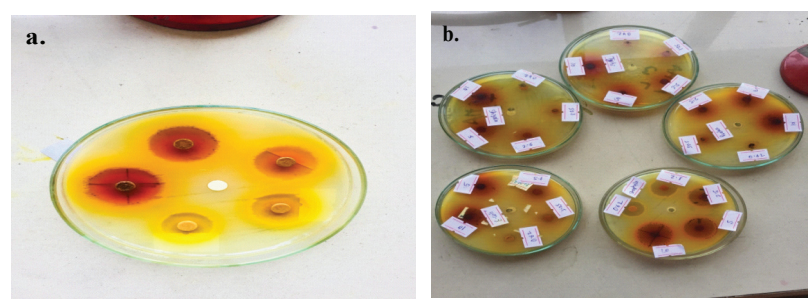

Fig. 1. (a) Zone of inhibition of S. aureus

(b) zone of inhibition of five different bacteria

\subsection{Antioxidant Activity}

The antioxidant activity was carried by using 1,1-diphenyl2-picrylhydrazyl or 2,2 diphenyl-2-picrylhydrazyl (DPPH). In this work the antioxidant activity of methanol extract was measured using standard DPPH assay. The DPPH radical scavenging activity was measured by spectrophotometric method and expressed in the percentage of antioxidant activity (AA\%) of each substance (Brand-Williams et al. 1995). In the reaction mixture, pure methanol was used as blank solution, methanol in DPPH without testing sample serves as, control and the sample were the extract of the plant. The free radical scavenging percentage was calculated by using following formula,
Scavenging $\%=100-\left[\frac{\text { Abs. of sample }- \text { Abs. of blank }}{\text { Absorbance of control }}\right] \times 100$

Fifty percent inhibitory concentration $\left(\mathrm{IC}_{50}\right)$ value is indicated as the effective concentration of the sample which is required to scavenge DPPH free radicals. By plotting extract concentration versus the corresponding scavenging effect, the inhibition curve was obtained, from which $\mathrm{IC}_{50}$ values were calculated.

\subsection{Preparation of the $0.5 \mathrm{mM}$ DPPH Solution}

A $0.5 \mathrm{mM}$ solution of DPPH was prepared by weighing $0.0197 \mathrm{~g}$ of the DPPH with care and dissolving it in methanol, and finally maintaining the volume up to 100 $\mathrm{mL}$. The solution was kept in a dark until use. Different concentrations of test samples of 50,100,150,200 $\mu \mathrm{g} /$ $\mathrm{mL}$ were made from the stock solution. Then $1.5 \mathrm{~mL}$ of all the test solutions were mixed with $1.5 \mathrm{~mL}$ of DPPH solution. The test tubes were shaken vigorously for the uniform mixing, and the solutions were kept for 30 minutes in the dark at room temperature. The control was prepared by mixing methanol and DPPH solution without the plant extracts (Methanol + DPPH). After 30 minutes, the total absorbance of the sample was measured at 517 $\mathrm{nm}$ using a UV-visible spectrophotometer. The different concentration of ascorbic acid of 50,100,150,200 $\mu \mathrm{g} /$ $\mathrm{mL}$ was prepared (standard), and the absorbance was also recorded spectrophotometrically at the same wavelength, and the calibration curve was plotted. The percentage radical scavenging activity (SCV\%) was determined by comparing with the methanol treated control group, and ascorbic acid as the positive control (Moharram \& Youssef 2014; Brand-Williams et al. 1995; Garcia et al. 2012; Aryal et al. 2020).

\section{RESULTS AND DISCUSSION}

\subsection{Phytochemical Analysis}

The different phytoconstituents present in methanol extract was identified using different chemical reagents following the standard phytochemical screening methods. The extract showed the presence of alkaloids, tannins, terpenoids, cardiac glycoside, saponins, steroids and reducing sugar. The major phytoconstituents on the bark of $M$. napaulensis were summarized in Table 1.

Table 1. Phytochemical constituents of methanol extract of bark of M. napaulensis

\begin{tabular}{|l|c|}
\hline Phytochemical screening & Methanolic extract \\
\hline Alkaloids & ++ \\
\hline Glycosides & ++ \\
\hline Cardiac glycosides & ++ \\
\hline
\end{tabular}




\begin{tabular}{|l|c|}
\hline Saponins & -- \\
\hline Tannins & ++ \\
\hline Terpenoids & ++ \\
\hline Flavonoids & -- \\
\hline Reducing sugar & ++ \\
\hline Steroids & ++ \\
\hline
\end{tabular}

$++=$ presence, $--=$ absence

Table 1 shows alkaloids, glycosides, cardiac glycosides, tannins, terpenoids, reducing sugar, but the absence of saponins and flavonoids in methanol extract.

\subsection{Antimicrobial Activity}

Antimicrobial activity of methanol extract against various human pathogens was determined by the disc diffusion method. Five microorganism cultures were used, namely S. aureus, Shigella spps, S. typhi, P. aeruginosa, and E. coli where the concentration of 10000, 5000, 2500, 1250, $625 \mu \mathrm{g} / \mathrm{mL}$ was prepared from the methanol extract. The zone of inhibition (ZOI) produced by the methanol extract of bark at varying concentrations against different bacteria was measured to estimate its antimicrobial activity and was tabulated in Table 2.

Table 2. Antimicrobial activity of methanol extract of $M$. napaulensis bark

\begin{tabular}{|l|c|c|c|c|c|}
\hline $\begin{array}{l}\text { Name of } \\
\text { bacteria }\end{array}$ & $\begin{array}{c}\text { Concentration } \\
\text { used }(\boldsymbol{\mu g} / \mathbf{m L})\end{array}$ & \multicolumn{3}{|c|}{$\begin{array}{c}\text { Zone of inhibition } \\
(\mathbf{m m})\end{array}$} & Average (mm) \\
\hline S. aureus & 10,000 & 29 & 25 & 28 & 27.3 \\
\cline { 2 - 6 } & 5,000 & 23 & 23 & 23 & 23 \\
\cline { 2 - 6 } & 2,500 & 21 & 21 & 21 & 21 \\
\cline { 2 - 6 } & 1,250 & 20 & 20 & 20 & 20 \\
\hline Shigella spps. & 625 & 18 & 18 & 18 & 18 \\
\cline { 2 - 6 } & 10,000 & 24 & 24 & 23 & 23.6 \\
\cline { 2 - 6 } & 5,000 & 20 & 20 & 20 & 20 \\
\cline { 2 - 6 } & 2,500 & 18 & 18 & 18 & 18 \\
\cline { 2 - 6 } & 1,250 & 15 & 15 & 15 & 15 \\
\hline \multirow{5}{*}{. typhi } & 625 & 14 & 15 & 15 & 14.7 \\
\cline { 2 - 6 } & 10,000 & 20 & 20 & 20 & 20 \\
\cline { 2 - 6 } & 5,000 & 16 & 16 & 16 & 16 \\
\cline { 2 - 6 } & 2,500 & 14 & 14 & 14 & 14 \\
\cline { 2 - 6 } & 1,250 & 12 & 12 & 12 & 12 \\
\hline P. aeruginosa & 625 & - & - & - & - \\
\cline { 2 - 6 } & 10,000 & 25 & 25 & 25 & 25 \\
\cline { 2 - 6 } & 5,000 & 23 & 23 & 23 & 23 \\
\cline { 2 - 6 } & 2,500 & 12 & 12 & 12 & 12 \\
\cline { 2 - 6 } & 1,250 & - & - & - & - \\
\hline E. coli & 625 & - & - & - & - \\
\cline { 2 - 6 } & 10,000 & 23 & 23 & 23 & 23 \\
\cline { 2 - 6 } & 5,000 & 22 & 22 & 22 & 22 \\
\cline { 2 - 6 } & 2,500 & 20 & 20 & 20 & 20 \\
\cline { 2 - 6 } & 1,250 & - & - & - & - \\
\cline { 2 - 6 } & 625 & - & - & - & \\
\hline
\end{tabular}

Note: Zone of inhibition for negative control was found to be $0 \mathrm{~mm}$

The antimicrobial activity showed that the activity of methanolic extract was best against $S$. aureus at every concentration (Table 2). The antimicrobial properties were determined by comparing with positive control chloramphenicol, which contained $30 \mu \mathrm{g} / \mathrm{disk}$ as represented in Table 3.
Table 3. Antimicrobial action of positive control (chloramphenicol)

\begin{tabular}{|l|c|}
\hline Name of bacteria & Zone of inhibition $\mathbf{( m m )}$ \\
\hline S. aureus & 25 \\
\hline Shigella spps. & 18 \\
\hline S. typhi & 26 \\
\hline P. aeruginosa & 21 \\
\hline E. coli & 20 \\
\hline
\end{tabular}

The extract had significant activity against other bacterial species but at a relatively high concentration, as shown in Fig. 2.

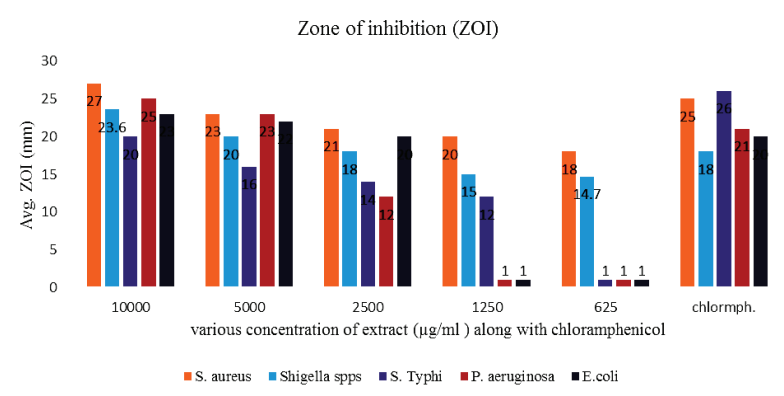

Fig. 2. Antimicrobial activities at different concentration of methanol extract and positive control in chloramphenicol

Fig. 2 shows different concentrations of the methanol extract against different human pathogens and ZOI produced by them. A similar experiment on the same plant using methanol extract of bark showed similar antimicrobial activity against the gram-positive $S$. aureus (Gyawali et al. 2020). Also an experiment with the same plant extract and against the same $S$. aureus but using its methanolic extract from stem showed the ZOI value of 18 mm (Thusa \& Mulmi 2017) which is relatively lower than experimental results from a bark extract. It may signify the possibly better antimicrobial activity by its methanol extract of the bark. These all relevant facts back up the important antimicrobial activity of the plant sample. Thus the relatively similar yet different antimicrobial activity of the same plant in all these experiments may direct toward the possible presence of phytochemicals in varying amounts when chosen from different places which may again open another area of scientific research (Gyawali et al. 2020; Thusa \& Mulmi 2017).

\subsection{DPPH Free Radical Scavenging Activity}

In this study the antioxidant activity of the bark of the $M$. nepaulensis in methanol extract was determined by using a 2,2-diphenyl-1-picrylhydrazyl (DPPH) radical scavenging assay. The activity was assessed using the mixture of DPPH with different concentration of extract solution at room temperature. Afterward, the absorbance value of 
each sample solution was recorded at $517 \mathrm{~nm}$. The same procedure was followed for the ascorbic acid, which served as standard antioxidant for this assay. The calibration curve for ascorbic acid was constructed to calculate $\mathrm{IC}_{50}$ value and this value was compared with $\mathrm{IC}_{50}$ value of methanolic extract (Fig. 3). The absorbance values of extract with different concentration have been tabulated in table 4 and compared with standard in Fig. 4.

Table 4. DPPH radical scavenging activity of the extract of $M$. napaulensis

\begin{tabular}{|c|c|c|c|}
\hline Concentration $(\mu \mathrm{g} / \mathrm{mL})$ & Absorbance & $\% \mathrm{SCV}$ & $\mathrm{IC}_{50}(\mu \mathrm{g} / \mathrm{mL})$ \\
\hline 50 & 0.2024 & 27.00 & \multirow{4}{*}{230.89} \\
\hline 100 & 0.2000 & 34.20 & \\
\hline 150 & 0.1925 & 42.14 & \\
\hline 200 & 0.1833 & 45.00 & \\
\hline
\end{tabular}

The values were executed, and $\mathrm{IC}_{50}$ was calculated with the help of Microsoft Excel. The regression line curve was plotted for the samples, and $\mathrm{IC}_{50}$ was found out; the same procedure was followed for ascorbic acid and presented in Fig. 3.

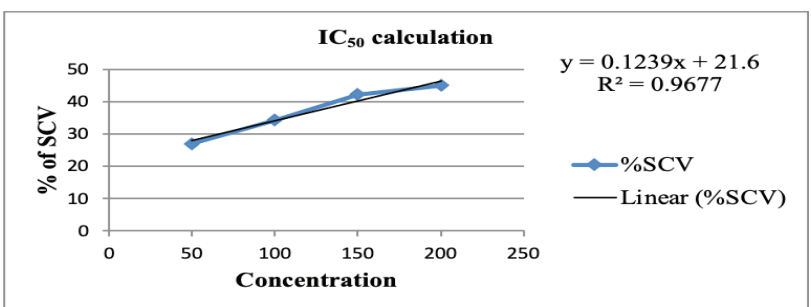

Fig. 3. Comparison of \% radical scavenging between ascorbic acid and M. napaulensis extract

Fig. 3 shows that $\mathrm{IC}_{50}$ value for the extract was found to be $230.89 \mu \mathrm{g} / \mathrm{mL}$. Also, following the same process, the $\mathrm{IC}_{50}$ value for ascorbic acid (standard) was assessed and found to be $182.73 \mu \mathrm{g} / \mathrm{mL}$, as shown in Fig. 4 .

\section{$I_{50}$ values $(\mu \mathrm{g} / \mathrm{mL})$}

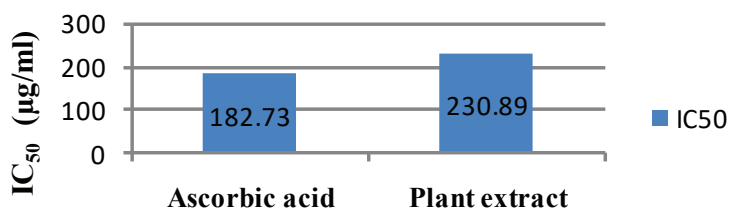

Fig. 4. The activity of both methanolic extract and ascorbic acid

Fig. 4 shows the activity of both extract and ascorbic acid as an antioxidant. These results explained the antioxidant activity of the methanol extract of the bark of $M$. napaulensis, which showed that the $M$. napaulensis plant had suitable antioxidant properties in bark.

\section{CONCLUSION}

Phytochemical screening of the bark of $M$. napaulensis extract showed the presence of phytochemicals like alkaloids, tannins, terpenoids, cardiac glycoside, steroids, reducing sugar. This fact shows the reason for the use of the plant traditionally as a therapeutic drug. The antimicrobial activities of the extract were assessed using a disc diffusion assay and compared to the zone of inhibition (ZOI). The methanol extract from the bark of plant at higher concentration clearly showed antimicrobial activity similar to chloramphenicol; although the antimicrobial property was shown in every selected bacterium, and also beneficial to $S$. aureus. The antioxidant property was studied using $\mathrm{DPPH}$ radical scavenging analysis and the $\mathrm{IC}_{50}$ value of methanol extract showed vigorous activities. The $\mathrm{IC}_{50}$ value for methanol extract was $230.89 \mu \mathrm{g} / \mathrm{mL}$, which was close to ascorbic acid (positive control), recorded as 182.73 $\mu \mathrm{g} / \mathrm{mL}$. These results provide qualitative evidence to support and justify the use of M. napaulensis as traditional ayurvedic medicine.

\section{ACKNOWLEDGMENT}

The authors would like to thank the Department of Chemistry, Tri-Chandra Multiple Campus, Ghantaghar, Kathmandu for technical support. Thanks also go to the Department of Pharmacy, Karnali College of Health Science, Gausala, Kathmandu for laboratory facilities.

\section{REFERENCES}

1. Amin, M., S.S.S. Mir and M.M.S. Jassal. 2013. Qualitative and quantitative analysis of phytochemicals of Taraxacum officinale. Wudpecker Journal of Pharmacy and Pharmacology 2: 001-005.

2. Andreicut, A-D., A.E. Parvu, C.M. Augustin, M. Parvu, E. Fischer-Fodor, V. Feldrihan, A.F. Catoi, M. Cecan and A. Irime. 2018. Phytochemical analysis of anti-inflammatory and antioxidant effect of mahonia aqifolium flower and fruit. FARMACIA 66: 49-58.

3. Aryal, S., S. Shrestha, A. Devkota, N.L. Bhandari and R. Jha. 2020. FTIR, GC-MS analysis and bioactivity studies of Withania somnifera L. of Nepalese origin. Journal of Nepal Chemical Society 41(1): 3645. DOI: https://doi.org/10.3126/ jncs.v41i1.30374

4. Basyal, D. and N.L. Bhandari. 2019. Phytochemical screening and cytotoxicity evaluation of ethanolic extract of Hypericum cordifolium (choisy) leaves. Journal of Nepal Chemical Society 40: 19-24. DOI: https://doi.org/10.3126/jncs.v40i0.27273. 
5. Bhandari, G., B. Pokhrel, Y. Oli, A. Katuwal and N.L. Bhandari. 2019. Screening of methicillin-resistant Staphylococcus aureus (MRSA) from wounds in pediatric patients visiting tertiary care in the hospital. Nepal Journal of Biotechnology 7: 82-89. DOI: https:// doi.org/10.3126/njb.v7i1.26957.

6. Bhandari, N. L., K.B. Kunwar Chhetri, D.P. Pandey and K.K. Nayak. 2017. Study of oil content in fruits of wild olive (Olea caspidata Wall. Ex G. Don) and its potential commercialization in Nepal. Journal of Nepal Chemical Society 36: 1-7.

7. Bhandari, N.L., K. Bist, J. Ghimire, S. Chaudhary, D.P. Pandey and R. Adhikari. 2020. Feasibility study of the Euphorbia pulcherrima plant extract as a natural dye with different mordants for fabric dyeing. Journal of Institute of Science and Technology 25(1): 30-36. DOI: https://doi.org/10.3126/jist.v25i1.29421.

8. Bhattrai, N. and K. Karki. 2004. Conservation and management of Himalayan medicinal plants in Nepal. General Technical Report-Pacific Northwest Research Station 45-50.

9. Brand-Williams, W., M.E. Cuvelier and C. Berset. 1995. Use of a free radical method to evaluate antioxidant activity. LWT - Food Science and Technology, 28(1): 25-30. DOI: 10.1016/s0023-6438(95)80008-5.

10. Che, C-T., V. George, T.P. Ijinu, P. Pushpangadan and K. Andrae-Marobela. 2017. Traditional Medicines, Pharmacognosy, fundamentals, applications, and strategies. (1 ${ }^{\text {st }}$ ed.) $15-30$. DOI: https://doi.org/10.1016/ B978-0-12-802104-0.00002-0.

11. Ekor, M. 2014. The growing use of herbal medicines: issues relating to adverse reactions and challenges in monitoring safety. Frontier in Pharmacology 4: 177. DOI: 10.3389/fphar.2013.00177.

12. Garcia, E.J., T.L.C. Oldoni, S.M. Alencar, A. Reis, A.D. Loguercio and R.H.M. Grande. 2012. Antioxidant activity by DPPH assay of potential solutions to be applied on bleached teeth. Brazilian Dental Journal 23: 22-27. DOI: https://doi.org/10.1590/S010364402012000100004 .

13. Gyawali, R., S. Adhikari, S. Gautam, P. Guragain, S. Pokharel, N. Pradhan, S. Sijapati and T.M. Shrestha. 2020. Antimicrobial and cytotoxic properties of selected medicinal plants from Kavrepalanchowk, Nepal. Banko Janakari 25(1): 15-19. DOI: doi. org/10.3126/banko.v25i1.13467.
14. Jian-Ming, H. and M. Qing. 2015. The medicinal uses of the genus Mahonia in traditional Chinese medicine: An ethnopharmacological, phytochemical and pharmacological review. Journal of Ethnopharmacology DOI: http://dx.doi.org/10.1016/j. jep.2015.09.013.

15. Lamichhane, B. 2014. Study of phytochemical, antioxidant, antimicrobial, and anticancer activity of Berberis aristata. The Journal of Tropical Life Science 4: 1-7.

16. Manandhar, N.P. 1991. Medicinal plant-lore of Tamang tribe of Kabhrepalanchok district, Nepal. Economic Botany 45: 58-71. DOI: https://doi.org/10.1007/ BF02860050.

17. Moharram H.A. and M.M. Youssef. 2014. Methods for determining the antioxidant activity: a review. Food Technology Department, National Research Dokki, Cairo, Egypt 11(1): 31-42.

18. Nguyen, T.L.A., J.H. Yoo, J.H. Park, N.H. Yoo, S.Y. Choi, B.J. Park, M.W. Choi and M.J. Kim. 2018. Study on anti-oxidative and anti-inflammatory activities in the stem of Mahonia napalensis DC. The Korean Society of Medicinal Crop Science 26: 71.

19. Riaz, H., A. Begum, S.A. Raza, Z. M-U-D. Khan, H. Yousuf and A. Tariq. 2015. Antimicrobial property and phytochemical study of ginger found in the local area of Punjab, Pakistan. International Current Pharmaceutical Journal 4(7): 405-409. DOI: https:// doi.org/10.3329/icpj.v4i7.23591.

20. Sibanda, T. and A.I. Okoh. 2007. The challenges of overcoming antibiotic resistance: plant extracts as potential sources of antimicrobial and resistance modifying agents. African Journal of Biotechnology $\mathbf{6}$ : 2886-2896.

21. Silwal, S.B., R. Adhikari, P. Lamichhane and N.L. Bhandari. 2020. Natural dyes as a photosensitizer in solar cells. BIBECHANA 17: 28-33. DOI: https://doi. org/10.3126/bibechana.v17i1.25599.

22. Singh, A., V. Bajpai, S. Kumar, A.K.S. Rawat and B. Kumar. 2017. Analysis of isoquinoline alkaloids from Mahonia leschenaultia and Mahonia napaulensis roots using UHPLC-Orbitrap-MS and UHPLC-Qq QLITMS/MS, Journal of pharmaceutical analysis 7: 77-86.

23. Stanković, N., T. Mihajilov-Krstev, B. Zlatković, V. Stankov-Jovanović, V. Mitić, J. Jović, and N. Bernstein. 2016. Antibacterial and antioxidant activity of 
traditional medicinal plants from the Balkan peninsula. NJAS - Wageningen Journal of Life Sciences 7: 2128. DOI:10.1016/j.njas.2015.12.006.

24. Tapsell, L.C., I. Hemphill, L. Cobiac, D.R. Sullivan, M. Fenech, C.S. Patch, S. Roodenrys, J.B. Keogh, P.M. Clifton, P.G. Williams, V.A. Fazio and K.E. Inge. 2006. Health benefits of herbs and spices: the past, the present, the future. Medical Journal of Australia 185: S1-S24.
25. Thusa, R. and S. Mulmi. 2017. Analysis of phytoconstituents and biological activities of different parts of Mahonia napalensis and Berberis aristata. Nepal Journal of Biotechnology 5: 5-13. DOI: https:// doi.org/10.3126/njb.v5i1.18864. 